\title{
Influence of different maintenance times of torque application on the removal torque values to loosen the prosthetic abutment screws of external hexagon implants
}

\author{
Sella, Gustavo Castellazzi ; Lopes Pereira Neto, Armando Rodrigues ; Maziero Volpato, Cláudia Angela ; de
} Vasconcellos, Diego Klee ; Pekkan, Gurel ; Özcan, Mutlu

\begin{abstract}
PURPOSE: To analyze the torque application on prosthetic abutment screws using different maintenance times, to determine an influence on the removal torque values. MATERIALS AND METHODS: A total of 40 external hexagon implants, 40 titanium screws, and 40 customized abutments were used. In group 1, the screws received a torque of $30 \mathrm{~N} \cdot \mathrm{cm}$ by instant torque application; in groups 2,3 , and 4, torque of $30 \mathrm{~N} \cdot \mathrm{cm}$ was applied and maintained for 10,20, and 30 seconds, respectively. Removal torque was performed 10 minutes after torque application. Data were statistically analyzed using 1-way ANOVA and Tukey HSD test $(\alpha=0.05)$. RESULTS: The mean and standard deviation $( \pm \mathrm{SD})$ of removal torque values found were $11.61 \pm 1.43 \mathrm{~N} \cdot \mathrm{cm}$ for group $1 ; 18.64 \pm$ $1.71 \mathrm{~N} \cdot \mathrm{cm}$ for group 2; $21.62 \pm 0.97 \mathrm{~N} \cdot \mathrm{cm}$ for group 3; and $21.48 \pm 1.55 \mathrm{~N} \cdot \mathrm{cm}$ for group 4. Groups 3 and 4 exhibited statistically higher values than group 2 , which demonstrated significantly higher values than group $1(\mathrm{P}<0.05)$. CONCLUSIONS: A torque of $30 \mathrm{~N} \cdot \mathrm{cm}$ applied for 20 seconds seemed to be the best option when considering the removal torque values of external hexagon implants.
\end{abstract}

DOI: https://doi.org/10.1097/ID.0b013e31829e548d

Posted at the Zurich Open Repository and Archive, University of Zurich

ZORA URL: https://doi.org/10.5167/uzh-89919

Journal Article

Accepted Version

Originally published at:

Sella, Gustavo Castellazzi; Lopes Pereira Neto, Armando Rodrigues; Maziero Volpato, Cláudia Angela; de Vasconcellos, Diego Klee; Pekkan, Gurel; Ȯzcan, Mutlu (2013). Influence of different maintenance times of torque application on the removal torque values to loosen the prosthetic abutment screws of external hexagon implants. Implant Dentistry, 22(5):534-539.

DOI: https://doi.org/10.1097/ID.0b013e31829e548d 
Influence of different maintenance times of torque application on the removal torque values to loosen the prosthetic abutment screws of external hexagon implants

AUTHORS: Gustavo Castellazzi Sella, MSc *, Armando Rodrigues Lopes Pereira Neto, MSc, $\mathrm{PhD}^{\S}$, Cláudia Ângela Maziero Volpato, MSc, $\mathrm{PhD}^{\dagger}$, Diego Klee de Vasconcellos, MSc ${ }^{\ddagger}$, Gurel Pekkan, DDS, PhD ^, Mutlu Özcan, Dr. Med. Dent., PhD ॥

\section{ABSTRACT: (178 WORDS)}

Purpose: To analyze the torque application on prosthetic abutment screws using different maintenance times, to determine an influence on the removal torque values.

Materials and Methods: A total of 40 external hexagon implants, 40 titanium screws and 40 customized abutments were used. In group 1, the screws received a torque of $30 \mathrm{Ncm}$ by instant torque application; in groups 2, 3 and 4, torque of $30 \mathrm{Ncm}$ was applied and maintained for 10, 20 and 30 seconds, respectively. Removal torque was performed 10 minutes after torque application. Data were statistically analyzed using one-way ANOVA and Tukey's HSD test $(\alpha=.05)$. Results: The mean and standard deviation $( \pm \mathrm{SD})$ of removal torque values found were $11.61 \pm 1.43 \mathrm{Ncm}$ for group $1 ; 18.64 \pm 1.71 \mathrm{Ncm}$ for group $2 ; 21.62 \pm 0.97 \mathrm{Ncm}$ for group 3 ; and $21.48 \pm 1.55 \mathrm{Ncm}$ for group 4. Groups 3 and 4 exhibited statistically higher values than group 2, which demonstrated significantly higher values than group $1(P<0.05)$. Conclusions: A torque of $30 \mathrm{Ncm}$ applied for 20 seconds seemed to be the best option when considering the removal torque values of external hexagon implants.

KEY WORDS: Dental implants; removal torque; detorque; abutment screw

* Lecturer, Federal University of Santa Catarina, Florianópolis, Santa Catarina, Brazil.

${ }^{\S}$ Lecturer, Federal University of Santa Catarina, Florianópolis, Santa Catarina, Brazil.

$\dagger$ Associate Professor, Partial Denture of the Federal University of Santa Catarina; Professor, Master in Dentistry, area of Prosthodontics/UFSC and Professor of the Specialization Course in Prosthodontics, Florianópolis, Santa Catarina, Brazil.

* Associate Professor, Partial Denture of the Federal University of Santa Catarina; Professor of the Specialization Course in Implantology at the Center for Teaching and Research on Dental 
Implants/UFSC; Professor of the Specialization Course in Prosthodontics, Florianópolis, Santa Catarina, Brazil.

ฯ Associate Professor, Department of Prosthodontics, Dumlupinar University, Faculty of Dentistry, Tavsanli Yolu 10. Km, 43270 Kutahya, Turkey.

॥ Professor, University of Zürich, Dental Materials Unit, Center for Dental and Oral Medicine, Clinic for Fixed and Removable Prosthodontics and Dental Materials Science, Zürich, Switzerland.

Reprint requests and correspondence to: Gürel Pekkan, DDS, $\mathrm{PhD}$, Dumlupinar University, Faculty of Dentistry, Tavsanli Yolu 10. Km, 43270 Kutahya, Turkey.

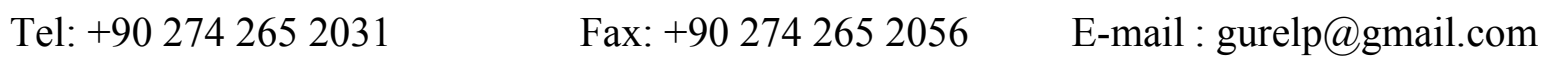


Screw loosening is a common problem associated with implant-supported prostheses. ${ }^{1,2}$ It causes inconvenience to the patient and practitioner, and can become financially onerous if it occurs frequently. ${ }^{3-5}$ Jemt $^{1}$ stated that only $69.3 \%$ of prostheses had stable gold screws at the first postinsertion examination. Another study specifically examined the incidence of loose occlusal screws in a population of patients whose prostheses had been in use for at least 5 years and reported that $40 \%$ of slot-headed occlusal screws and $10 \%$ of screws with an internal hexagon were loose. ${ }^{6}$ Nissan et al. $^{2}$ reported abutment screw loosening in screw-retained $32 \%$ and in cement-retained $9 \%$ restorations in a long term outcome study of implant-supported fixed partial dental restorations followed up to 15 years. Screw loosening seemed to occur most often with single-tooth implant-supported restorations. ${ }^{7-9}$

The screw loosening may be related to several factors, including: screw tightening, quality of the prosthetic components, screw design, plastic deformation of contact surfaces and lack of passive fit. ${ }^{10-16}$ To prevent this problem, a number of modifications have been used, including modification of the implant body abutment interface (external or internal hexagon or octagon), use of gold screws, torque-controlling devices, screw cements, and the use of a silicone obturator and washers between the prostheses and screws. ${ }^{1,5,7,8,17,18}$ Also, centering the occlusal contact, flattening cuspal inclination, narrowing the buccolingual width of the crown, and reducing the cantilever length are some of the recommended procedures to overcome this problem. ${ }^{13,19-22}$

The mechanics of screws have been investigated in the dental literature. ${ }^{5}$ After application of a torque on the head of a screw, a clamping/tensile force called preload is generated on the screw threads' keeping the implant and prosthesis tightly together under all static and functional conditions. ${ }^{7,9}$ When the contacting surfaces are under compression, surface imperfections lead to increased friction and decreased preload. ${ }^{23,24}$ Some researchers estimate that up to $10 \%$ of the initial preload may be lost due to surface imperfections in the first seconds after torque application. ${ }^{13,21,25}$ The amount of preload present at the threads of a prosthetic retaining screw 
depends on the applied torque, the presence and type of lubricant, the physical properties of the materials in contact, and settling of the screw after initial torquing. ${ }^{26,27}$

Higher torque usually leads to greater preload values. ${ }^{26,27}$ Conversely, excessive torque yields permanent deformation on the screw threads, potentially leading to fracture in the long term, due to the fatigue associated with mastication forces. ${ }^{27}$ Thus, the application of adequate torque is fundamental in reducing screw loosening and avoiding screw fracture. Previous studies have demonstrated that the stress generated on the screw threads by an ideal preload should be $60 \%$ to $75 \%$ of the elasticity limit of the material employed for fabrication of the abutment screw. ${ }^{28-30}$

The external hexagonal system is in the form of a protruding hexagon for dental implant systems. ${ }^{13,23}$ The mechanism of the external hexagonal type implant abutment screw loosening and torque loss was already explained in many previous papers. ${ }^{6,7,13,15,21,23,29,31,32}$ Researchers have suggested that repeated tightening of screws removes small irregularities on the mating surfaces, which in turn reduces the friction at the surfaces and leads to higher preload. ${ }^{13,14,16,25}$ In contrast, preload may not be easily maintained with reduced frictional resistance when functional forces exceed it. ${ }^{23}$ Therefore, it is advised that torque/detorque cycles are minimized both in laboratory and clinical routines. ${ }^{15,16,25}$ As an alternative method to repeated tightening method, the torque maintenance time may be extended during torque application in a single screw tightening procedure. In the literature, no data exist on the effect of torque maintenance times of torque application on detorque values in external hexagon type implant abutment screws. This in-vitro study investigated if torque application on prosthetic abutment screws, with different maintenance times (10, 20 and 30 seconds), influence the removal torque values when compared to the instant screw tightening technique. The null hypothesis tested was that the different maintenance times do not influence the removal torque values when compared to the instant screw tightening technique. 
The study was conducted on 40 external hexagon implants (Master Porous 518710 - Conexão Sistemas de Prótese, São Paulo, Brazil) with 3.75-mm diameter and 10-mm length, 40 customized titanium abutments (Munhão 128021 - Conexão Sistemas de Prótese, São Paulo, Brazil) and 40 square titanium screws (121024 - Conexão Sistemas de Prótese, São Paulo, Brazil - Titanium) (Fig. 1). The abutments were fixated on the implants with the titanium screws, using a hand-held screwdriver (06210099 - Conexão Sistemas de Prótese, São Paulo, Brazil) until resistance was felt. However, torque was not applied with the hand-held screwdriver. (au: please specify what type of Titanium: CP/ Grade? Alloy?. Also please indicate type of thread etc...

\section{Titanium Screw 121024 - Titanium Ti 6Al 4V}

\section{Thread design (Metric thread M2.0; pitch: $0.4 \mathrm{~mm}$}

The implants were randomly assigned in 4 groups with 10 implants each, on which the abutment screws were submitted to different times of torque maintenance (Table 1). A digital torque meter (AFTI Advanced Force \& Torque Indicator - Mecmesin - Horsham, United Kingdom) (Fig. 2) was used. The implants were individually fixated in one mandrel of the torque meter and tight in mandrel with a manual force sufficient to prevent its rotation during application of torque. A modified square screwdriver was inserted in the torque wrench (40000 Conexão Sistemas de Prótese - São Paulo, Brazil), which differs from the conventional screwdriver only for the presence of a rod with 2-cm length and 2-mm diameter on one end. This end was connected to the other mandrel of the digital torque meter, whose function was only to position the screwdriver on the same rotation axis of the implant/abutment/screw assembly. Thus, the screwdriver was kept free in the mandrel, which only guided the movement during torque/detorque application (Fig. 3).

Similar to clinical torque application as recommended by the manufacturer, a torque of $30 \mathrm{Ncm}$ was applied by the rod of the manual torque meter for the times established for each group. As the 
torque was applied, it was controlled by the digital torque meter, whose display recorded the torque applied accurately and instantaneously, so that any variations in the torque would be immediately corrected and kept as close to $30.0 \mathrm{Ncm}$ as possible.

Ten minutes after torque application for the times suggested for each group, as assessed by a digital chronometer, the manual torque meter was adjusted for detorque, using the same devices employed for torque application. The maximum torque removal value was immediately recorded on the display of the digital torque meter and recorded on a table.

The procedure was repeated ten times on all abutment screws of each group. The removal torque values were registered and data were statistically analyzed using SPSS 11.0 software for Windows (SPSS Inc., Chicago, IL, USA). The statistical analysis included calculating the means and standard deviations of all groups which were then submitted to Analysis of Variance (ANOVA) and comparisons of the mean removal torque values between groups by the Tukey's HSD test.

\section{RESULTS}

The mean removal torque values after 10 minutes were $11.61 \mathrm{Ncm}(\mathrm{SD} \pm 1.43 \mathrm{Ncm})$ for group 1 , $18.64 \mathrm{Ncm}(\mathrm{SD} \pm 1.71 \mathrm{Ncm})$ for group 2, $21.62 \mathrm{Ncm}(\mathrm{SD} \pm 0.97 \mathrm{Ncm})$ for group 3 and $21.48 \mathrm{Ncm}$ $(\mathrm{SD} \pm 1.55 \mathrm{Ncm})$ for group 4 .

ANOVA indicated significant differences among groups $(P<0.05)$. Post-hoc comparisons were made by the Tukey's HSD test $(P<0.05)$, and indicated statistically significant difference between all groups, except between groups 3 and 4, which were statistically similar (Table 2).

\section{DISCUSSION}


In some studies, the abutment screw is recommended to be tightened once with the recommended torque and then tightened again a few minutes later to minimize the embedment relaxation between mating threads, thus assisting to achieve the optimum preload. ${ }^{25,31,32}$ However, in daily practice it would be more practical way to tighten the abutment screw in a single tightening procedure with an appropriate method. Therefore, in this study, it was aimed to investigate the removal torque values of different maintenance times of torque application using a single screw tightening procedure.

The results of this study revealed that different torque maintenance times of torque application affected the removal torque values. There was significant difference among removal torque values after instant torque application, 10 and 20 or $30 \mathrm{sec}$ torque maintenance times. Therefore, the null hypothesis that the different maintenance times do not influence the removal torque values when compared to the instant screw tightening technique was rejected. Statistical analysis of the results demonstrated that torque maintenance for 10,20 or 30 seconds promoted a significant increase in the removal torque values required for screw loosening when compared to the instant torque application. The removal torque value in group 1 was lower when compared to group 2, which in turn was lower than groups 3 and 4, which were statistically similar to each other. These results corroborate the assumption that, when torque is maintained for a certain time (groups 2, 3 and 4), a great part of the plastic deformation occurring mainly in the first seconds is compensated, avoiding excessive loss of the removal torque value when compared to the group submitted to instant torque application (group 1). In the current study, with the extended torque maintenance time (10 to 30 seconds), the minimization of embedment relaxation between the mating threads might be achieved. The mechanical deformation of abutment screws that were subjected repeated tightening procedure might also be simulated. The decrease in preload, which could occur due to the corrections of surface irregularities after instant torque application might be compensated with the better adaptation and friction of the contacting surfaces when the maintenance time is prolonged. 
In the current study, the removal torque values were lower than the initial torque values. The results of the present study agree with previous studies, which demonstrated that the removal torque values measured after torque application on abutment screws were always lower than the initial torque values. ${ }^{23,24-26}$ Concerning the removal torque immediately after torque application, previous studies ${ }^{23,33}$ demonstrated a considerable loss, ranging from $11 \%$ to $35 \%$ of the torque value. In the present study, the loss of the torque applied after ten minutes was $61.3 \%$ for group 1 , $37.9 \%$ for group $2,27.9 \%$ for group 3 and $28.4 \%$ for group 4 , demonstrating a significantly greater percentage of retaining torque in groups 3 and 4.

Some authors have reported that the friction is greater for the first screw tightening and loosening and is reduced after repeated cycles of tightening and loosening. ${ }^{34}$ It is believed that the initial cycles of screw tightening and loosening remove irregularities of the threads produced during machining of the screws, implants and prosthetic abutments, smoothing the surfaces and reducing the frictional forces. ${ }^{14,16,23}$ This factor is directly related to the coefficient of friction, which is controlled in the manufacturing process and is influenced by the metallurgical properties of the components, design and quality of finishing of the surfaces of screws and implants. ${ }^{33,35}$ Therefore, some studies demonstrate that the reuse of a screw allows greater preload production with the same torque applied. ${ }^{25,28}$ Especially, the reuse of gold screws allows greater preload production whereas the titanium screws reveal constant preload values when reused. Variables, such as geometric design factors (the thread pitch and implant complex dimensions), the material properties of the components, and environmental conditions such as the state of lubrication at mating surfaces should be also be taken into consideration. Nonetheless, in this study, minimal variables were included in order to investigate the effect of torque maintenance time on removal torque values. When working with machined components, some errors may be introduced in each abutment screw or implant during fabrication. However, this study used an adequate sample size of new components (implants, abutments and titanium screws) to minimize these variables. The present 
study also did not aim to compare the removal torque values after repeated cycles of screw tightening and loosening.

A single operator conducted the experiment. Despite this, the rate of torque application, time to reach the maximum torque ${ }^{36}$ and torque value applied may alter the removal torque value, which may not be identically reproduced for all specimens. To avoid these factors and standardize the torque applied, an electrical device (Torque handpiece Controller, Nobel Biocare AB, Karlskoga, Sweden) may be used. ${ }^{35}$ When this device is used, there may be a slight variation in the torque applied, which may be influenced by the axial load during application. However, this electrical device interrupts the torque application when the programmed torque is reached, which precluded its use in the present study, because the desired torque should be maintained for 10,20 and 30 seconds in groups 2, 3 and 4, respectively.

A previous study ${ }^{35}$ mentioned the occurrence of large variations in the torque value when a mechanical torque wrench was used, due to the corrosion caused by the sterilization process. However, a new mechanical torque wrench and a digital torque measuring device were used in the present study, in order to minimize the variations that might occur upon torque application, allowing the desired torque maintenance for 10, 20 and 30 seconds in groups 2, 3 and 4, respectively.

The presence and quantity of lubricant (saliva or blood) between the components may affect the coefficient of friction, which is reduced as the quantity of lubricant is increased. ${ }^{26}$ The present invitro study estimated the torque required to loosen the screws when considering a condition without humidity. Therefore, it is assumed that the removal torque values found in this study would be different than expected in clinical conditions. 
The torque loss observed, in the present study, occurred in an in-vitro situation, without the application of any external force, different from the clinical environment, in which the implant and prostheses are subjected to dynamical forces. A previous study ${ }^{37}$ demonstrated that a single application of a physiological load on a cantilever prosthesis may cause loss of preload on the prosthetic screw. Another study ${ }^{38}$ revealed that the retention mechanism of implant screws is significantly affected in-vivo by functional and parafunctional forces. Thus, the present results probably underestimate the torque loss that occurs clinically. Even though plastic deformation is unavoidable during tightening of prosthetic screws, the search for the highest preload possible is fundamental for the stability and success of implant-supported prostheses.

Accurate materials and procedures are recommended to achieve the best preload possible on implant-supported prostheses, minimizing the deformation caused by surface irregularities. This highlights the importance of investigating mechanisms to control the deformation of implantsupported metallic frameworks, in an attempt to enhance the preload and prosthetic stability. The recommended tightening torque values of abutment screws are different in different implantabutment systems. In the study of Tsuge and Hagiwara ${ }^{13} 20 \mathrm{Ncm}$ tightening torque was applied for tightening Ti Screws of external hexagonal implants and abutments whereas, Khraisat et al. ${ }^{39}$ used the CeraOne abutments in their experiment and the recommended tightening torque was $32 \mathrm{Ncm}$. Asvanund and Morgano $^{29}$ used $35 \mathrm{Ncm}$ tightening torque for connecting external hexagon abutments in their study model. It must be highlighted that differences in abutment screw type, material and the tightening torque greatly influence preload.

The results of the present in-vitro study demonstrated that torque maintenance for 10,20 and 30 seconds are better options when compared to instant torque application, promoting higher removal torque values 10 minutes after torque application. The torque of $30 \mathrm{Ncm}$ applied for 20 seconds seemed to be the best option when considering the higher removal torque values compared to the 
torque application for 10 seconds, and was similar to the value observed for torque application for 30 seconds, with the advantage of reducing the time of torque maintenance by 10 seconds.

This simple, accessible and low-cost procedure reduces preload loss on the prosthetic screws, enhancing the torque required for screw loosening. Therefore, the present results encourage the recommendation of applying and maintaining torque for 20 seconds on the prosthetic screws.

There are some limitations of this study. No comparisons were made between the removal torque values of torque application after repeated screw tightening procedures and a single tightening procedure with torque application using different torque maintenance times. Further studies are needed on this context using scanning electron microscopy (SEM) for the evaluation of screw surfaces for better interpretation of the effects of each procedure to the surface texture of the screws. Also, a study set-up using eccentric cyclic loading in preferably simulated body fluid is needed to test the effects of different variables to each procedure in external hexagonal implantabutment-screw complex.

\section{CONCLUSION}

According to the results achieved and within the experimental conditions investigated, it was concluded that the application of a torque of $30 \mathrm{Ncm}$ for 10,20 or 30 seconds are better options when compared to the instant torque application in external hexagon implants. The torque of 30 Ncm applied for 20 seconds seemed to be the best option when considering the higher removal torque values compared to the instant torque application and to torque application for 10 seconds, and considering the similar value observed for torque application for 30 seconds.

\section{ACKNOWLEDGMENTS}

The authors gratefully acknowledge the support of Conexão Sistemas de Prótese for supplying the test components used in this study. 


\section{DISCLOSURE}

The authors declare no conflict of interest.

\section{REFERENCES}

1. Jemt T. Failures and complications in 391 consecutively inserted fixed prostheses supported by Brånemark implants in edentulous jaws: A study of treatment from the time of prosthesis placement to the first annual checkup. Int J Oral Maxillofac Implants. 1991;6:270-276.

2. Nissan J, Narobai D, Gross O, et al. Long-term outcome of cemented versus screw-retained implant-supported partial restorations. Int J Oral Maxillofac Implants. 2011;26:1102-1107.

3. Jemt T, Laney WR, Harris D, et al. Osseointegrated implants for single tooth replacement: a 1-year report from a multicenter prospective study. Int J Oral Maxillofac Implants. 1991;6:2936.

4. Lewis SG, Llamas D, Avera S. The UCLA abutment: a four year review. J Prosthet Dent. 1992;67:509-515.

5. Taylor TD. Prosthodontic problems and limitations associated with osseointegration. $J$ Prosthet Dent. 1998;79:74-78.

6. Kallus T, Bessing C. Loose gold screws frequently occur in full-arch fixed prostheses supported by osseointegrated implants after 5 years. Int J Oral Maxillofac Implants. 1994;9:169178.

7. McGlumphy EA, Mendel DA, Holloway JA. Implant screw mechanics. Dent Clin North Am. 1998;42:71-89.

8. Levine RA, Clem DS 3rd, Wilson TG Jr, et al. Multicenter retrospective analysis of the ITI implant system used for single-tooth replacements: results of loading for 2 or more years. Int $J$ Oral Maxillofac Implants. 1999;14:516-520.

9. Jörnéus L, Jemt T, Carlsson L. Loads and designs of screw joints for single crowns supported by osseointegrated implants. Int J Oral Maxillofac Implants. 1992;7:353-359. 
10. Eliasson A, Eriksson T, Johansson A, et al. Fixed partial prostheses supported by 2 or 3 implants: a retrospective study up to 18 years. Int J Oral Maxillofac Implants. 2006;21:567-574.

11. Barbosa GA, Bernardes SR, das Neves FD, et al. Relation between implant/abutment vertical misfit and torque loss of abutment screws. Braz Dent J. 2008;19:358-363.

12. Schmitt J, Holst S, Eitner S, et al. Prosthetic screw torque removal values in implants retained as cast bar superstructures or bars modified by the Cresco Ti Precision technique--a comparative in vivo study. Int J Prosthodont. 2009;22:193-200.

13. Tsuge T, Hagiwara Y.Influence of lateral-oblique cyclic loading on abutment screw loosening of internal and external hexagon implants. Dent Mater J. 2009;28:373-381.

14. Guzaitis KL, Knoernschild KL, Viana MA. Effect of repeated screw joint closing and opening cycles on implant prosthetic screw reverse torque and implant and screw thread morphology. J Prosthet Dent. 2011;106:159-169.

15. Barbosa GS, Silva-Neto JP, Simamoto-Júnior PC, et al. Evaluation of screw loosening on new abutment screws and after successive tightening. Braz Dent J. 2011;22:51-55.

16. Yao KT, Kao HC, Cheng CK, et al. The effect of clockwise and counterclockwise twisting moments on abutment screw loosening. Clin Oral Implants Res. 2012;23:1181-1186.

17. Hurson S. Practical clinical guidelines to prevent screw loosening. Int J Dent Symp. $1995 ; 3: 22-25$.

18. Cho SC, Small PN, Elian N, et al. Screw loosening for standard and wide diameter implants in partially edentulous cases: 3- to 7-year longitudinal data. Implant Dent. 2004;13:245250.

19. Weinberg LA. Reduction of implant loading using a modified centric occlusal anatomy. Int J Prosthodont. 1998;11:55-69.

20. English CE. Biomechanical concerns with fixed partial dentures involving implants. Implant Dent. 1993;2:221-242.

21. Shigley JE, Mischke CR. Standard Handbook of Machine Design, 2nd ed, McGraw-Hill, New York, 1996, pp.16-23, 39. 
22. Haas R, Mensdorff-Pouilly N, Mailath G, et al. Brånemark single tooth implants: a preliminary report of 76 implants. J Prosthet Dent. 1995;73:274-279.

23. Assunção WG, Delben JA, Tabata LF, et al. Preload evaluation of different screws in external hexagon joint. Implant Dent. 2012;21:46-50.

24. Stüker RA, Teixeira ER, Beck JC, et al. Preload and torque removal evaluation of three different abutment screws for single standing implant restorations. J Appl Oral Sci. 2008;16:5558.

25. Cardoso M, Torres MF, Lourenço EJ, et al. Torque removal evaluation of prosthetic screws after tightening and loosening cycles: an in vitro study. Clin Oral Implants Res. 2012;23:475-480.

26. Burguete RI, Johns RB, King $\mathrm{T}$, et al. Tightening characteristics for screw joints in osseointegrated dental implants. J Prosthet Dent. 1994;71:592-599.

27. Haack JE, Sakaguchi RL, Sun T, et al. Elongation and preload stress in dental implant abutment screws. Int J Oral Maxillofac Implants. 1995;10:529-536.

28. Saboury A, Neshandar Asli H, Vaziri S. The Effect of Repeated Torque in Small Diameter Implants with Machined and Premachined Abutments. Clin Implant Dent Relat Res. 2012;14:e224230.

29. Asvanund P, Morgano SM. Photoelastic stress analysis of external versus internal implantabutment connections. J Prosthet Dent. 2011;106:266-271.

30. Kim SK, Koak JY, Heo SJ, et al. Screw loosening with interchangeable abutments in internally connected implants after cyclic loading. Int J Oral Maxillofac Implants. 2012;27:42-47.

31. Breeding LC, Dixon DL, Nelson EW, et al. Torque required to loosen single-tooth implant abutment screws before and after simulated function. Int J Prosthodont. 1993;6:435-439.

32. Dixon DL, Breeding LC, Sadler JP, et al. Comparison of screw loosening, rotation, and deflection among three implant designs. J Prosthet Dent. 1995;74:270-278.

33. Weiss EI, Kozak D, Gross MD. Effect of repeated closures on opening torque values in seven abutment-implant systems. J Prosthet Dent. 2000;84:194-199. 
34. Haack JE, Sakaguchi RL, Sun T, et al. Elongation and preload stress in dental implant abutment screws. Int J Oral Maxillofac Implants. 1995;10:529-536.

35. Korioth TWP, Cardoso AC, Versluis A. Effect of washers on reverse torque displacement of dental implant gold retaining screws. J Prosthet Dent. 2001;82:312-316.

36. Cantwell A, Hobkirk JA. Preload loss in gold prosthesis-retaining screws as a function of time. Int J Oral Maxillofac Implants. 2004;19:124-132.

37. Rangert B, Gunne J, Sullivan DY. Mechanical aspects of a Brånemark implant connected to a natural tooth: An in vitro study. Int J Oral Maxillofac Implants. 1991;6:177-186.

38. Balik A, Ozdemir Karatas M, Keskin H. Effects of different abutment connection designs on the force distribution around commercially available dental implants: a $3 \mathrm{~d}$ finite element analysis. J Oral Implantol. 2012;38:491-496.

39. Khraisat A, Hashimoto A, Nomura S, et al. Effect of lateral cyclic loading on abutment screw loosening of an external hexagon implant system. J Prosthet Dent. 2004;91:326-34. 


\section{LEGENDS}

Table 1. Time of torque maintenance of torque $(30 \mathrm{Ncm})$ application for the groups $1,2,3$ and 4 .

Table 2. Mean removal torque values and standard deviation $( \pm \mathrm{SD})$ for groups $1,2,3$ and 4 .

Results were statistical categorized according to Tukey’s HSD test $(P<.05)$.

Fig. 1. The view of external hexagon implant, customized titanium abutment and titanium screw used in this study.

Fig. 2. Digital torque meter on left-hand side and the mandrels of torque testing assembly on righthand side.

Fig. 3. Application of $30 \mathrm{Ncm}$ torque by the rod of the manual torque meter positioned between the two mandrels of the digital torque meter. 
Influence of different maintenance times of torque application on the removal torque values to loosen the prosthetic abutment screws of external hexagon implants

AUTHORS: Gustavo Castellazzi Sella, MSc *, Armando Rodrigues Lopes Pereira Neto, MSc, $\mathrm{PhD}^{\S}$, Cláudia Ângela Maziero Volpato, MSc, $\mathrm{PhD}^{\dagger}$, Diego Klee de Vasconcellos, MSc ${ }^{\ddagger}$, Gurel Pekkan, DDS, PhD ", Mutlu Özcan, Dr. Med. Dent., PhD ॥

\section{ABSTRACT: (178 WORDS)}

Purpose: To analyze the torque application on prosthetic abutment screws using different maintenance times, to determine an influence on the removal torque values.

Materials and Methods: A total of 40 external hexagon implants, 40 titanium screws and 40 customized abutments were used. In group 1, the screws received a torque of $30 \mathrm{Ncm}$ by instant torque application; in groups 2, 3 and 4, torque of $30 \mathrm{Ncm}$ was applied and maintained for 10, 20 and 30 seconds, respectively. Removal torque was performed 10 minutes after torque application. Data were statistically analyzed using one-way ANOVA and Tukey's HSD test $(\alpha=.05)$. Results: The mean and standard deviation $( \pm \mathrm{SD})$ of removal torque values found were $11.61 \pm 1.43 \mathrm{Ncm}$ for group $1 ; 18.64 \pm 1.71 \mathrm{Ncm}$ for group $2 ; 21.62 \pm 0.97 \mathrm{Ncm}$ for group 3 ; and $21.48 \pm 1.55 \mathrm{Ncm}$ for group 4. Groups 3 and 4 exhibited statistically higher values than group 2, which demonstrated significantly higher values than group $1(P<0.05)$. Conclusions: A torque of $30 \mathrm{Ncm}$ applied for 20 seconds seemed to be the best option when considering the removal torque values of external hexagon implants.

KEY WORDS: Dental implants; removal torque; detorque; abutment screw

* Lecturer, Federal University of Santa Catarina, Florianópolis, Santa Catarina, Brazil.

${ }^{\S}$ Lecturer, Federal University of Santa Catarina, Florianópolis, Santa Catarina, Brazil.

${ }^{\dagger}$ Associate Professor, Partial Denture of the Federal University of Santa Catarina; Professor, Master in Dentistry, area of Prosthodontics/UFSC and Professor of the Specialization Course in Prosthodontics, Florianópolis, Santa Catarina, Brazil. 
*Associate Professor, Partial Denture of the Federal University of Santa Catarina; Professor of the Specialization Course in Implantology at the Center for Teaching and Research on Dental Implants/UFSC; Professor of the Specialization Course in Prosthodontics, Florianópolis, Santa Catarina, Brazil.

『 Associate Professor, Department of Prosthodontics, Dumlupinar University, Faculty of Dentistry, Tavsanli Yolu 10. Km, 43270 Kutahya, Turkey.

॥ Professor, University of Zürich, Dental Materials Unit, Center for Dental and Oral Medicine, Clinic for Fixed and Removable Prosthodontics and Dental Materials Science, Zürich, Switzerland.

Reprint requests and correspondence to: Gürel Pekkan, $\mathrm{DDS}, \mathrm{PhD}$, Dumlupinar University, Faculty of Dentistry, Tavsanli Yolu 10. Km, 43270 Kutahya, Turkey.

Tel: +902742652031＜noBreak>Ｆax: +902742652056Ｅ-mail : gurelp@gmail.com 
Screw loosening is a common problem associated with implant-supported prostheses. ${ }^{1,2}$ It causes inconvenience to the patient and practitioner, and can become financially onerous if it occurs frequently. ${ }^{3-5}$ Jemt $^{1}$ stated that only $69.3 \%$ of prostheses had stable gold screws at the first postinsertion examination. Another study specifically examined the incidence of loose occlusal screws in a population of patients whose prostheses had been in use for at least 5 years and reported that $40 \%$ of slot-headed occlusal screws and $10 \%$ of screws with an internal hexagon were loose. ${ }^{6}$ Nissan et al. $^{2}$ reported abutment screw loosening in screw-retained $32 \%$ and in cement-retained $9 \%$ restorations in a long term outcome study of implant-supported fixed partial dental restorations followed up to 15 years. Screw loosening seemed to occur most often with single-tooth implant-supported restorations. ${ }^{7-9}$

The screw loosening may be related to several factors, including: screw tightening, quality of the prosthetic components, screw design, plastic deformation of contact surfaces and lack of passive fit. ${ }^{10-16}$ To prevent this problem, a number of modifications have been used, including modification of the implant body abutment interface (external or internal hexagon or octagon), use of gold screws, torque-controlling devices, screw cements, and the use of a silicone obturator and washers between the prostheses and screws. ${ }^{1,5,7,8,17,18}$ Also, centering the occlusal contact, flattening cuspal inclination, narrowing the buccolingual width of the crown, and reducing the cantilever length are some of the recommended procedures to overcome this problem. ${ }^{13,19-22}$

The mechanics of screws have been investigated in the dental literature. ${ }^{5}$ After application of a torque on the head of a screw, a clamping/tensile force called preload is generated on the screw threads' keeping the implant and prosthesis tightly together under all static and functional conditions. ${ }^{7,9}$ When the contacting surfaces are under compression, surface imperfections lead to increased friction and decreased preload. ${ }^{23,24}$ Some researchers estimate that up to $10 \%$ of the initial preload may be lost due to surface imperfections in the first seconds after torque application. ${ }^{13,21,25}$ The amount of preload present at the threads of a prosthetic retaining screw 
depends on the applied torque, the presence and type of lubricant, the physical properties of the materials in contact, and settling of the screw after initial torquing. ${ }^{26,27}$

Higher torque usually leads to greater preload values. ${ }^{26,27}$ Conversely, excessive torque yields permanent deformation on the screw threads, potentially leading to fracture in the long term, due to the fatigue associated with mastication forces. ${ }^{27}$ Thus, the application of adequate torque is fundamental in reducing screw loosening and avoiding screw fracture. Previous studies have demonstrated that the stress generated on the screw threads by an ideal preload should be $60 \%$ to $75 \%$ of the elasticity limit of the material employed for fabrication of the abutment screw. ${ }^{28-30}$

The external hexagonal system is in the form of a protruding hexagon for dental implant systems. ${ }^{13,23}$ The mechanism of the external hexagonal type implant abutment screw loosening and torque loss was already explained in many previous papers. ${ }^{6,7,13,15,21,23,29,31,32}$ Researchers have suggested that repeated tightening of screws removes small irregularities on the mating surfaces, which in turn reduces the friction at the surfaces and leads to higher preload. ${ }^{13,14,16,25}$ In contrast, preload may not be easily maintained with reduced frictional resistance when functional forces exceed it. ${ }^{23}$ Therefore, it is advised that torque/detorque cycles are minimized both in laboratory and clinical routines. ${ }^{15,16,25}$ As an alternative method to repeated tightening method, the torque maintenance time may be extended during torque application in a single screw tightening procedure. In the literature, no data exist on the effect of torque maintenance times of torque application on detorque values in external hexagon type implant abutment screws. This in-vitro study investigated if torque application on prosthetic abutment screws, with different maintenance times (10, 20 and 30 seconds), influence the removal torque values when compared to the instant screw tightening technique. The null hypothesis tested was that the different maintenance times do not influence the removal torque values when compared to the instant screw tightening technique. 
The study was conducted on 40 external hexagon implants (Master Porous 518710 - Conexão Sistemas de Prótese, São Paulo, Brazil) with 3.75-mm diameter and 10-mm length, 40 customized titanium abutments (Munhão 128021 - Conexão Sistemas de Prótese, São Paulo, Brazil) and 40 square titanium screws (121024 - Conexão Sistemas de Prótese, São Paulo, Brazil - Titanium) (Fig. 1). The abutments were fixated on the implants with the titanium screws, using a hand-held screwdriver (06210099 - Conexão Sistemas de Prótese, São Paulo, Brazil) until resistance was felt. However, torque was not applied with the hand-held screwdriver. (au: please specify what type of Titanium: CP/ Grade? Alloy?. Also please indicate type of thread etc...

\section{Titanium Screw 121024 - Titanium Ti 6Al 4V}

\section{Thread design (Metric thread M2.0; pitch: $0.4 \mathrm{~mm}$}

The implants were randomly assigned in 4 groups with 10 implants each, on which the abutment screws were submitted to different times of torque maintenance (Table 1). A digital torque meter (AFTI Advanced Force \& Torque Indicator - Mecmesin - Horsham, United Kingdom) (Fig. 2) was used. The implants were individually fixated in one mandrel of the torque meter and tight in mandrel with a manual force sufficient to prevent its rotation during application of torque. A modified square screwdriver was inserted in the torque wrench (40000 Conexão Sistemas de Prótese - São Paulo, Brazil), which differs from the conventional screwdriver only for the presence of a rod with 2-cm length and 2-mm diameter on one end. This end was connected to the other mandrel of the digital torque meter, whose function was only to position the screwdriver on the same rotation axis of the implant/abutment/screw assembly. Thus, the screwdriver was kept free in the mandrel, which only guided the movement during torque/detorque application (Fig. 3).

Similar to clinical torque application as recommended by the manufacturer, a torque of $30 \mathrm{Ncm}$ was applied by the rod of the manual torque meter for the times established for each group. As the 
torque was applied, it was controlled by the digital torque meter, whose display recorded the torque applied accurately and instantaneously, so that any variations in the torque would be immediately corrected and kept as close to $30.0 \mathrm{Ncm}$ as possible.

Ten minutes after torque application for the times suggested for each group, as assessed by a digital chronometer, the manual torque meter was adjusted for detorque, using the same devices employed for torque application. The maximum torque removal value was immediately recorded on the display of the digital torque meter and recorded on a table.

The procedure was repeated ten times on all abutment screws of each group. The removal torque values were registered and data were statistically analyzed using SPSS 11.0 software for Windows (SPSS Inc., Chicago, IL, USA). The statistical analysis included calculating the means and standard deviations of all groups which were then submitted to Analysis of Variance (ANOVA) and comparisons of the mean removal torque values between groups by the Tukey's HSD test.

\section{RESULTS}

The mean removal torque values after 10 minutes were $11.61 \mathrm{Ncm}(\mathrm{SD} \pm 1.43 \mathrm{Ncm})$ for group 1 , $18.64 \mathrm{Ncm}(\mathrm{SD} \pm 1.71 \mathrm{Ncm})$ for group 2, $21.62 \mathrm{Ncm}(\mathrm{SD} \pm 0.97 \mathrm{Ncm})$ for group 3 and $21.48 \mathrm{Ncm}$ $(\mathrm{SD} \pm 1.55 \mathrm{Ncm})$ for group 4 .

ANOVA indicated significant differences among groups $(P<0.05)$. Post-hoc comparisons were made by the Tukey's HSD test $(P<0.05)$, and indicated statistically significant difference between all groups, except between groups 3 and 4, which were statistically similar (Table 2).

\section{DISCUSSION}


In some studies, the abutment screw is recommended to be tightened once with the recommended torque and then tightened again a few minutes later to minimize the embedment relaxation between mating threads, thus assisting to achieve the optimum preload. ${ }^{25,31,32}$ However, in daily practice it would be more practical way to tighten the abutment screw in a single tightening procedure with an appropriate method. Therefore, in this study, it was aimed to investigate the removal torque values of different maintenance times of torque application using a single screw tightening procedure.

The results of this study revealed that different torque maintenance times of torque application affected the removal torque values. There was significant difference among removal torque values after instant torque application, 10 and 20 or $30 \mathrm{sec}$ torque maintenance times. Therefore, the null hypothesis that the different maintenance times do not influence the removal torque values when compared to the instant screw tightening technique was rejected. Statistical analysis of the results demonstrated that torque maintenance for 10,20 or 30 seconds promoted a significant increase in the removal torque values required for screw loosening when compared to the instant torque application. The removal torque value in group 1 was lower when compared to group 2, which in turn was lower than groups 3 and 4, which were statistically similar to each other. These results corroborate the assumption that, when torque is maintained for a certain time (groups 2, 3 and 4), a great part of the plastic deformation occurring mainly in the first seconds is compensated, avoiding excessive loss of the removal torque value when compared to the group submitted to instant torque application (group 1). In the current study, with the extended torque maintenance time (10 to 30 seconds), the minimization of embedment relaxation between the mating threads might be achieved. The mechanical deformation of abutment screws that were subjected repeated tightening procedure might also be simulated. The decrease in preload, which could occur due to the corrections of surface irregularities after instant torque application might be compensated with the better adaptation and friction of the contacting surfaces when the maintenance time is prolonged. 
In the current study, the removal torque values were lower than the initial torque values. The results of the present study agree with previous studies, which demonstrated that the removal torque values measured after torque application on abutment screws were always lower than the initial torque values. ${ }^{23,24-26}$ Concerning the removal torque immediately after torque application, previous studies ${ }^{23,33}$ demonstrated a considerable loss, ranging from $11 \%$ to $35 \%$ of the torque value. In the present study, the loss of the torque applied after ten minutes was $61.3 \%$ for group 1 , $37.9 \%$ for group $2,27.9 \%$ for group 3 and $28.4 \%$ for group 4 , demonstrating a significantly greater percentage of retaining torque in groups 3 and 4.

Some authors have reported that the friction is greater for the first screw tightening and loosening and is reduced after repeated cycles of tightening and loosening. ${ }^{34}$ It is believed that the initial cycles of screw tightening and loosening remove irregularities of the threads produced during machining of the screws, implants and prosthetic abutments, smoothing the surfaces and reducing the frictional forces. ${ }^{14,16,23}$ This factor is directly related to the coefficient of friction, which is controlled in the manufacturing process and is influenced by the metallurgical properties of the components, design and quality of finishing of the surfaces of screws and implants. ${ }^{33,35}$ Therefore, some studies demonstrate that the reuse of a screw allows greater preload production with the same torque applied. ${ }^{25,28}$ Especially, the reuse of gold screws allows greater preload production whereas the titanium screws reveal constant preload values when reused. Variables, such as geometric design factors (the thread pitch and implant complex dimensions), the material properties of the components, and environmental conditions such as the state of lubrication at mating surfaces should be also be taken into consideration. Nonetheless, in this study, minimal variables were included in order to investigate the effect of torque maintenance time on removal torque values. When working with machined components, some errors may be introduced in each abutment screw or implant during fabrication. However, this study used an adequate sample size of new components (implants, abutments and titanium screws) to minimize these variables. The present 
study also did not aim to compare the removal torque values after repeated cycles of screw tightening and loosening.

A single operator conducted the experiment. Despite this, the rate of torque application, time to reach the maximum torque ${ }^{36}$ and torque value applied may alter the removal torque value, which may not be identically reproduced for all specimens. To avoid these factors and standardize the torque applied, an electrical device (Torque handpiece Controller, Nobel Biocare AB, Karlskoga, Sweden) may be used. ${ }^{35}$ When this device is used, there may be a slight variation in the torque applied, which may be influenced by the axial load during application. However, this electrical device interrupts the torque application when the programmed torque is reached, which precluded its use in the present study, because the desired torque should be maintained for 10,20 and 30 seconds in groups 2, 3 and 4, respectively.

A previous study ${ }^{35}$ mentioned the occurrence of large variations in the torque value when a mechanical torque wrench was used, due to the corrosion caused by the sterilization process. However, a new mechanical torque wrench and a digital torque measuring device were used in the present study, in order to minimize the variations that might occur upon torque application, allowing the desired torque maintenance for 10, 20 and 30 seconds in groups 2, 3 and 4, respectively.

The presence and quantity of lubricant (saliva or blood) between the components may affect the coefficient of friction, which is reduced as the quantity of lubricant is increased. ${ }^{26}$ The present invitro study estimated the torque required to loosen the screws when considering a condition without humidity. Therefore, it is assumed that the removal torque values found in this study would be different than expected in clinical conditions. 
The torque loss observed, in the present study, occurred in an in-vitro situation, without the application of any external force, different from the clinical environment, in which the implant and prostheses are subjected to dynamical forces. A previous study ${ }^{37}$ demonstrated that a single application of a physiological load on a cantilever prosthesis may cause loss of preload on the prosthetic screw. Another study ${ }^{38}$ revealed that the retention mechanism of implant screws is significantly affected in-vivo by functional and parafunctional forces. Thus, the present results probably underestimate the torque loss that occurs clinically. Even though plastic deformation is unavoidable during tightening of prosthetic screws, the search for the highest preload possible is fundamental for the stability and success of implant-supported prostheses.

Accurate materials and procedures are recommended to achieve the best preload possible on implant-supported prostheses, minimizing the deformation caused by surface irregularities. This highlights the importance of investigating mechanisms to control the deformation of implantsupported metallic frameworks, in an attempt to enhance the preload and prosthetic stability. The recommended tightening torque values of abutment screws are different in different implantabutment systems. In the study of Tsuge and Hagiwara ${ }^{13} 20 \mathrm{Ncm}$ tightening torque was applied for tightening Ti Screws of external hexagonal implants and abutments whereas, Khraisat et al. ${ }^{39}$ used the CeraOne abutments in their experiment and the recommended tightening torque was $32 \mathrm{Ncm}$. Asvanund and Morgano $^{29}$ used $35 \mathrm{Ncm}$ tightening torque for connecting external hexagon abutments in their study model. It must be highlighted that differences in abutment screw type, material and the tightening torque greatly influence preload.

The results of the present in-vitro study demonstrated that torque maintenance for 10,20 and 30 seconds are better options when compared to instant torque application, promoting higher removal torque values 10 minutes after torque application. The torque of $30 \mathrm{Ncm}$ applied for 20 seconds seemed to be the best option when considering the higher removal torque values compared to the 
torque application for 10 seconds, and was similar to the value observed for torque application for 30 seconds, with the advantage of reducing the time of torque maintenance by 10 seconds.

This simple, accessible and low-cost procedure reduces preload loss on the prosthetic screws, enhancing the torque required for screw loosening. Therefore, the present results encourage the recommendation of applying and maintaining torque for 20 seconds on the prosthetic screws.

There are some limitations of this study. No comparisons were made between the removal torque values of torque application after repeated screw tightening procedures and a single tightening procedure with torque application using different torque maintenance times. Further studies are needed on this context using scanning electron microscopy (SEM) for the evaluation of screw surfaces for better interpretation of the effects of each procedure to the surface texture of the screws. Also, a study set-up using eccentric cyclic loading in preferably simulated body fluid is needed to test the effects of different variables to each procedure in external hexagonal implantabutment-screw complex.

\section{CONCLUSION}

According to the results achieved and within the experimental conditions investigated, it was concluded that the application of a torque of $30 \mathrm{Ncm}$ for 10,20 or 30 seconds are better options when compared to the instant torque application in external hexagon implants. The torque of 30 Ncm applied for 20 seconds seemed to be the best option when considering the higher removal torque values compared to the instant torque application and to torque application for 10 seconds, and considering the similar value observed for torque application for 30 seconds.

\section{ACKNOWLEDGMENTS}

The authors gratefully acknowledge the support of Conexão Sistemas de Prótese for supplying the test components used in this study. 


\section{DISCLOSURE}

The authors declare no conflict of interest.

\section{REFERENCES}

40. Jemt T. Failures and complications in 391 consecutively inserted fixed prostheses supported by Brånemark implants in edentulous jaws: A study of treatment from the time of prosthesis placement to the first annual checkup. Int J Oral Maxillofac Implants. 1991;6:270-276.

41. Nissan J, Narobai D, Gross O, et al. Long-term outcome of cemented versus screw-retained implant-supported partial restorations. Int J Oral Maxillofac Implants. 2011;26:1102-1107.

42. Jemt T, Laney WR, Harris D, et al. Osseointegrated implants for single tooth replacement: a 1-year report from a multicenter prospective study. Int J Oral Maxillofac Implants. 1991;6:2936.

43. Lewis SG, Llamas D, Avera S. The UCLA abutment: a four year review. J Prosthet Dent. 1992;67:509-515.

44. Taylor TD. Prosthodontic problems and limitations associated with osseointegration. $J$ Prosthet Dent. 1998;79:74-78.

45. Kallus $\mathrm{T}$, Bessing C. Loose gold screws frequently occur in full-arch fixed prostheses supported by osseointegrated implants after 5 years. Int J Oral Maxillofac Implants. 1994;9:169178.

46. McGlumphy EA, Mendel DA, Holloway JA. Implant screw mechanics. Dent Clin North Am. 1998;42:71-89.

47. Levine RA, Clem DS 3rd, Wilson TG Jr, et al. Multicenter retrospective analysis of the ITI implant system used for single-tooth replacements: results of loading for 2 or more years. Int $J$ Oral Maxillofac Implants. 1999;14:516-520.

48. Jörnéus L, Jemt $\mathrm{T}$, Carlsson L. Loads and designs of screw joints for single crowns supported by osseointegrated implants. Int J Oral Maxillofac Implants. 1992;7:353-359. 
49. Eliasson A, Eriksson T, Johansson A, et al. Fixed partial prostheses supported by 2 or 3 implants: a retrospective study up to 18 years. Int J Oral Maxillofac Implants. 2006;21:567-574.

50. Barbosa GA, Bernardes SR, das Neves FD, et al. Relation between implant/abutment vertical misfit and torque loss of abutment screws. Braz Dent J. 2008;19:358-363.

51. Schmitt J, Holst S, Eitner S, et al. Prosthetic screw torque removal values in implants retained as cast bar superstructures or bars modified by the Cresco Ti Precision technique--a comparative in vivo study. Int J Prosthodont. 2009;22:193-200.

52. Tsuge T, Hagiwara Y.Influence of lateral-oblique cyclic loading on abutment screw loosening of internal and external hexagon implants. Dent Mater J. 2009;28:373-381.

53. Guzaitis KL, Knoernschild KL, Viana MA. Effect of repeated screw joint closing and opening cycles on implant prosthetic screw reverse torque and implant and screw thread morphology. J Prosthet Dent. 2011;106:159-169.

54. Barbosa GS, Silva-Neto JP, Simamoto-Júnior PC, et al. Evaluation of screw loosening on new abutment screws and after successive tightening. Braz Dent J. 2011;22:51-55.

55. Yao KT, Kao HC, Cheng CK, et al. The effect of clockwise and counterclockwise twisting moments on abutment screw loosening. Clin Oral Implants Res. 2012;23:1181-1186.

56. Hurson S. Practical clinical guidelines to prevent screw loosening. Int J Dent Symp. $1995 ; 3: 22-25$.

57. Cho SC, Small PN, Elian N, et al. Screw loosening for standard and wide diameter implants in partially edentulous cases: 3- to 7-year longitudinal data. Implant Dent. 2004;13:245250.

58. Weinberg LA. Reduction of implant loading using a modified centric occlusal anatomy. Int J Prosthodont. 1998;11:55-69.

59. English CE. Biomechanical concerns with fixed partial dentures involving implants. Implant Dent. 1993;2:221-242.

60. Shigley JE, Mischke CR. Standard Handbook of Machine Design, 2nd ed, McGraw-Hill, New York, 1996, pp.16-23, 39. 
61. Haas R, Mensdorff-Pouilly N, Mailath G, et al. Brånemark single tooth implants: a preliminary report of 76 implants. J Prosthet Dent. 1995;73:274-279.

62. Assunção WG, Delben JA, Tabata LF, et al. Preload evaluation of different screws in external hexagon joint. Implant Dent. 2012;21:46-50.

63. Stüker RA, Teixeira ER, Beck JC, et al. Preload and torque removal evaluation of three different abutment screws for single standing implant restorations. J Appl Oral Sci. 2008;16:5558.

64. Cardoso M, Torres MF, Lourenço EJ, et al. Torque removal evaluation of prosthetic screws after tightening and loosening cycles: an in vitro study. Clin Oral Implants Res. 2012;23:475-480.

65. Burguete RI, Johns RB, King $\mathrm{T}$, et al. Tightening characteristics for screw joints in osseointegrated dental implants. J Prosthet Dent. 1994;71:592-599.

66. Haack JE, Sakaguchi RL, Sun T, et al. Elongation and preload stress in dental implant abutment screws. Int J Oral Maxillofac Implants. 1995;10:529-536.

67. Saboury A, Neshandar Asli H, Vaziri S. The Effect of Repeated Torque in Small Diameter Implants with Machined and Premachined Abutments. Clin Implant Dent Relat Res. 2012;14:e224230.

68. Asvanund P, Morgano SM. Photoelastic stress analysis of external versus internal implantabutment connections. J Prosthet Dent. 2011;106:266-271.

69. Kim SK, Koak JY, Heo SJ, et al. Screw loosening with interchangeable abutments in internally connected implants after cyclic loading. Int J Oral Maxillofac Implants. 2012;27:42-47.

70. Breeding LC, Dixon DL, Nelson EW, et al. Torque required to loosen single-tooth implant abutment screws before and after simulated function. Int J Prosthodont. 1993;6:435-439.

71. Dixon DL, Breeding LC, Sadler JP, et al. Comparison of screw loosening, rotation, and deflection among three implant designs. J Prosthet Dent. 1995;74:270-278.

72. Weiss EI, Kozak D, Gross MD. Effect of repeated closures on opening torque values in seven abutment-implant systems. J Prosthet Dent. 2000;84:194-199. 
73. Haack JE, Sakaguchi RL, Sun T, et al. Elongation and preload stress in dental implant abutment screws. Int J Oral Maxillofac Implants. 1995;10:529-536.

74. Korioth TWP, Cardoso AC, Versluis A. Effect of washers on reverse torque displacement of dental implant gold retaining screws. J Prosthet Dent. 2001;82:312-316.

75. Cantwell A, Hobkirk JA. Preload loss in gold prosthesis-retaining screws as a function of time. Int J Oral Maxillofac Implants. 2004;19:124-132.

76. Rangert B, Gunne J, Sullivan DY. Mechanical aspects of a Brånemark implant connected to a natural tooth: An in vitro study. Int J Oral Maxillofac Implants. 1991;6:177-186.

77. Balik A, Ozdemir Karatas M, Keskin H. Effects of different abutment connection designs on the force distribution around commercially available dental implants: a $3 \mathrm{~d}$ finite element analysis. J Oral Implantol. 2012;38:491-496.

78. Khraisat A, Hashimoto A, Nomura S, et al. Effect of lateral cyclic loading on abutment screw loosening of an external hexagon implant system. J Prosthet Dent. 2004;91:326-34. 


\section{LEGENDS}

Table 1. Time of torque maintenance of torque $(30 \mathrm{Ncm})$ application for the groups $1,2,3$ and 4 .

Table 2. Mean removal torque values and standard deviation $( \pm \mathrm{SD})$ for groups $1,2,3$ and 4 .

Results were statistical categorized according to Tukey’s HSD test $(P<.05)$.

Fig. 1. The view of external hexagon implant, customized titanium abutment and titanium screw used in this study.

Fig. 2. Digital torque meter on left-hand side and the mandrels of torque testing assembly on righthand side.

Fig. 3. Application of $30 \mathrm{Ncm}$ torque by the rod of the manual torque meter positioned between the two mandrels of the digital torque meter. 
